\title{
Veículos Aéreos Não Tripulados (VANT) para inspeção de manifestações patológicas em fachadas com revestimento cerâmico
}

\author{
Unmanned Aerial Vehicles (UAV) for inspection of \\ pathological manifestations on ceramic coated facades
}

\section{Ramiro Daniel Ballesteros Alberto Casado Lordsleem Junior}

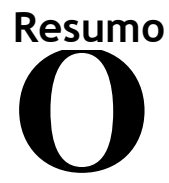

mundo passa por uma revolução de ordem abrangente, destacando-se a demanda por inserção tecnológica nos processos industriais, notadamente pela necessidade da otimização do tempo. Em especial, os veículos aéreos não tripulados (VANT), ou “drones", estão tendo crescente relevância como novo mecanismo de obtenção de dados e inspeções visuais, mais ágeis e seguros. Este artigo teve o objetivo de realizar o estudo experimental do uso de VANT como ferramenta visual para inspeção de manifestações patológicas em fachadas de edifícios. A metodologia contemplou a realização de dois estudos de caso em edificações de mediana e grande altura, em que foram contempladas as etapas de coleta de imagens e processamento. Os resultados da pesquisa exibiram a viabilidade técnica e a eficácia da inspeção, e mostraram que entre os ativos visuais produzidos as fotografias digitais geradas pela aeronave foram mais efetivas para a detecção de manifestações patológicas quando comparadas com os modelos gerados pelo software Agisoft PhotoScan. Como principal contribuição, têm-se a validação do pacote tecnológico destinado a auxiliar no diagnóstico de manifestações patológicas a partir da formulação do protocolo para a inspeção de fachadas com uso de VANT e a análise comparativa dos ativos visuais que podem ser gerados.

Palavras-chave: VANT. Drone. Inspeção predial. Inspeção visual. Monitoramento. Fotos aéreas.
Abstract
The world is undergoing a revolution, with high demand for the use of technology in industrial processes notably due to the need for optimisation of time, which poses a significant challenge. Hence, unmanned aerial vehicles $(U A V s)$ are becoming increasingly relevant as novel, more agile and secure devices.This study was aimed at performing an exploratory study of the use of UAVs as a tool for the visual inspection of pathological manifestations in building facades. The methodology included experimental research, where two case studies were carried out in buildings of medium and high height, developing for these purposes the protocol of activities, where the image collection and processing stages were contemplated. Thus, the results proved the technical feasibility and efficacy of the inspection, showing that among the visual assets produced, the digital photographs generated by the aircraft were more effective in detecting pathologies than the models generated by the
Agisoft PhotoScan software. The main contribution of this study is the validation of the technological package designed to assist in the diagnosis of pathological manifestations based on the formulation of a protocol for facade inspections using UAVs and a comparative analysis of the visual assets that can be generated.
Keywords: UAV. Building inspection. Visual inspection. Monitoring. Aerial photos.

${ }^{2}$ Alberto Casado Lordsleem Junior 2Universidade de Pernambuco Recife - PE - Brasil

Recebido em 26/08/19

Aceito em 02/06/20 


\section{Introdução}

Os requisitos de desempenho das construções necessitam ser estabelecidos na etapa de projeto, para permitir que o edifício tenha capacidade de suportar a ação dos agentes de degradação por um tempo predeterminado ou previsto (POSSAN; DEMOLINER, 2013). Durante a vida útil são necessárias atividades de manutenção para conservar ou recuperar a capacidade funcional da edificação e seus sistemas constituintes, viabilizando, assim, atender a critérios de segurança e às necessidades dos usuários.

Nesse contexto, a inspeção visual de fachadas da edificação é uma atividade de grande importância, visto que a fachada é a principal responsável pelo desempenho da edificação, tendo a função de protegê-lo contra os agentes de degradação externos e de proporcionar conforto funcional e estético a seus usuários (BAUER; MILHOMEM; AIDAR, 2018; JUST; FRANCO, 2001).

A inspeção visual de fachadas tem como propósito avaliar o estado de conservação da vedação vertical e os diferentes elementos que a compõem, fornecendo diretrizes para uma manutenção eficaz e de custobenefício adequado. Com essa prática pode-se garantir o bom funcionamento do subsistema vedação vertical, de forma a cumprir as funções para as quais foi construído e, possivelmente, ser estendida sua vida útil.

Para esse fim, o método eficaz e mais seguro que reduz tanto o tempo quanto o custo da inspeção é a inspeção visual com uso de veículo aéreo não tripulado (VANT), também conhecido como drone (MELO; COSTA, 2015). Com ajuda dessa tecnologia é possível realizar uma filmagem completa e captura de fotografias em alta resolução (High Definition - HD). A inspeção através do VANT pode registrar problemas não observados a olho nu do térreo, como infiltrações, descolamentos ou furos no revestimento e/ou fissuras e trincas nas fachadas.

O VANT é uma classe de aeronaves pilotadas remotamente ou de forma automática por meio da utilização de coordenadas predefinidas, uma tecnologia emergente, conhecida historicamente por seu papel em aplicações militares (IRIZARRY; COSTA, 2016).

Tanto no Brasil quanto em outros países, o uso potencial desses veículos aéreos em ambientes civis vem se tornando cada dia mais comum em áreas como agricultura, silvicultura, arqueologia, arquitetura e construção civil. O que era exclusividade de uso militar agora também está presente em vários outros setores, destacando-se que os usos de VANT pelos militares são totalmente diferentes das atuais e corriqueiras aplicações civis, com seus diferentes tipos, o que traz uma maneira inovadora para a utilização dessa ferramenta tecnológica.

Mais especificamente, pode-se destacar o uso de VANT com o intuito de auxiliar atividades de gerenciamento de obras, principalmente no que diz respeito à logística de canteiro, monitoramento e acompanhamento do processo evolutivo da obra, além de permitir inspeções visuais em locais de difícil acesso, como edifícios de grande altura (HUNG et al., 2018).

O levantamento fotográfico de fachadas através de VANT pode diminuir as variáveis custo e tempo, quando comparadas com o método tradicional de inspeção - alpinismo industrial (ACOSTA et al., 2019; REAGAN; SABATO; NIEZRECKI, 2017).

Nos últimos anos, diferentes estudos científicos vêm se desenvolvendo utilizando VANT como ferramenta de inspeção visual, essencialmente para diversos elementos de infraestrutura.

Autores como Young e Seonghyuk (2019), Koutsoudis et al. (2019) e Patriota (2017) estudaram o uso de VANT para a inspeção e documentação digital tridimensional do patrimônio cultural, com resultados promissores quanto à reconstrução geométrica digital das edificações analisadas.

Já Serrat et al. (2019), Kerle et al. (2019) e Melo Junior (2016) destacam o potencial de eficácia de VANT na inspeção de fachadas, permitindo detectar tanto danos estruturais quanto estéticos nas edificações.

Entretanto, existe uma lacuna relativa ao uso dessa tecnologia para a inspeção de fachadas com revestimentos cerâmicos, particularmente em edificações de mediana e grande altura, em que o VANT oferece mais vantagens, principalmente pela versatilidade na locomoção multidireccional (vertical e horizontal) característica dessa aeronave (KERLE et al., 2019).

Dessa forma, é importante comprovar experimentalmente a eficácia do VANT para a inspeção de manifestações patológicas nessas condições, considerando ainda as diferenças intrínsecas inerentes ao tipo de revestimento. Deve-se enfatizar também que o uso do revestimento cerâmico tem elevada frequência de uso em diferentes regiões do Brasil, especialmente em edificações situadas em zonas litorâneas, que 
apresentam grande número de manifestações patológicas, motivadas pela agressividade do meio em que se encontram (JUST; FRANCO, 2001).

Este artigo objetiva discutir a aplicabilidade técnica do VANT para a inspeção de manifestações patológicas em edifícios de média e grande altura com revestimento cerâmico por meio da validação experimental de um pacote tecnológico constituído por aeronave, câmera digital embarcada e software de processamento de imagens, todos comercialmente à disposição das empresas e profissionais que fazem vistorias de fachadas.

Busca-se realizar análise comparativa entre os três tipos de recursos visuais mais comuns decorrentes do uso do VANT (fotografias digitais, modelos tridimensionais e ortomosaicos) e seu desempenho para a inspeção visual, dando uma contribuição científica em função da validação do procedimento e da identificação do tipo de recurso visual mais apropriado para a detecção de manifestações patológicas.

\section{Manifestações patológicas em revestimentos cerâmicos de fachadas}

O sistema de revestimento cerâmico de fachada destaca-se pela estética e valorização do imóvel. Devido ao fato de o material possuir status de bom, bonito e relativamente barato, é usado intensamente pelas maiores construtoras brasileiras em edifícios residenciais, comerciais e industriais (COSTA et al., 2019).

De acordo com Just e Franco (2001), não há outro material utilizado em fachadas que possa apresentar a riqueza de composições e durabilidade do revestimento cerâmico com um custo tão acessível. Entre suas principais características técnicas destacam-se a resistência à abrasão, absorção de água, resistência ao manchamento e resistência ao ataque de agentes químicos (HORSTH et al., 2018).

Porém, um aspecto importante inerente ao sistema de revestimento cerâmico de fachada é o grande número de insumos envolvidos em sua produção. Nesse processo, todos os componentes podem, de alguma forma, alterar ou comprometer o desempenho global, através das características da base, das argamassas de emboço e de assentamento, da placa cerâmica, do rejunte e das juntas (LOPES et al., 2018).

Como consequência, o controle da produção fica dificultado pelo elevado número de variáveis envolvidas, e diversos equívocos têm sido cometidos na utilização do revestimento cerâmico para fachada, que, junto à agressividade do meio, geram a ocorrência de manifestações patológicas (ALMEIDA, 2004; JUST; FRANCO, 2001).

As manifestações patológicas incidentes nos revestimentos cerâmicos de fachada podem apresentar-se de maneiras distintas. Assim, as consequências podem ir desde problemas estéticos ou de desempenho do revestimento aos riscos de acidentes com pessoas, substancialmente agravados pela altura dos edifícios (COSTA et al., 2019; ALMEIDA, 2004).

Segundo Costa et al. (2019), Lopes et al. (2018), Horsth et al. (2018), Freitas, França e França (2013) e Galletto e Andrello (2013), os principais tipos de manifestações patológicas mais associadas aos revestimentos cerâmicos de fachada são fissuras, trincas, eflorescência, destacamento e manifestações patológicas decorrentes de processos biológicos (Figura 1).

Uma vez identificado o problema, considera-se razoável promover a manutenção, visto que uma manifestação patológica pode provocar outras ainda mais graves, alertam Lopes et al. (2018). Nesse sentido, faz-se necessário executar inspeções periodicamente a fim de realizar a detecção precoce das manifestações e prevenir danos maiores na edificação, evitando-se novas manutenções corretivas e reduzindo significativamente o custo dos reparos (HORSTH et al., 2018). A manutenção se dá após uma inspeção e análise do problema, para que sejam escolhidos tratamentos adequados, que garantirão sua eficácia.

Atualmente, no Brasil, a inspeção de manifestações patológicas em fachadas de edifícios de média e grande altura é realizada comumente pelo método tradicional, que inclui o alpinista industrial. De acordo com Aguilar (2018), o profissional desse ramo pode realizar a verificação visual e o registro fotográfico dos principais pontos a serem analisados.

Esse método de inspeção visual é realizado por meio de descidas com balancins individuais do tipo "cadeirinha", desde a cobertura até o pavimento térreo, de forma a abranger toda a área das fachadas, e com registro fotográfico, o que permite uma avaliação do estado de conservação geral do elemento e uma análise inicial das manifestações patológicas existentes. Em suma, esse método de inspeção também permite a realização de testes de percussão, o que possibilita a detecção das áreas com som cavo e, portanto, com prováveis problemas de aderência do revestimento cerâmico (VDR, 2019). 
Figura 1 - Manifestações patológicas associadas a revestimentos cerâmicos

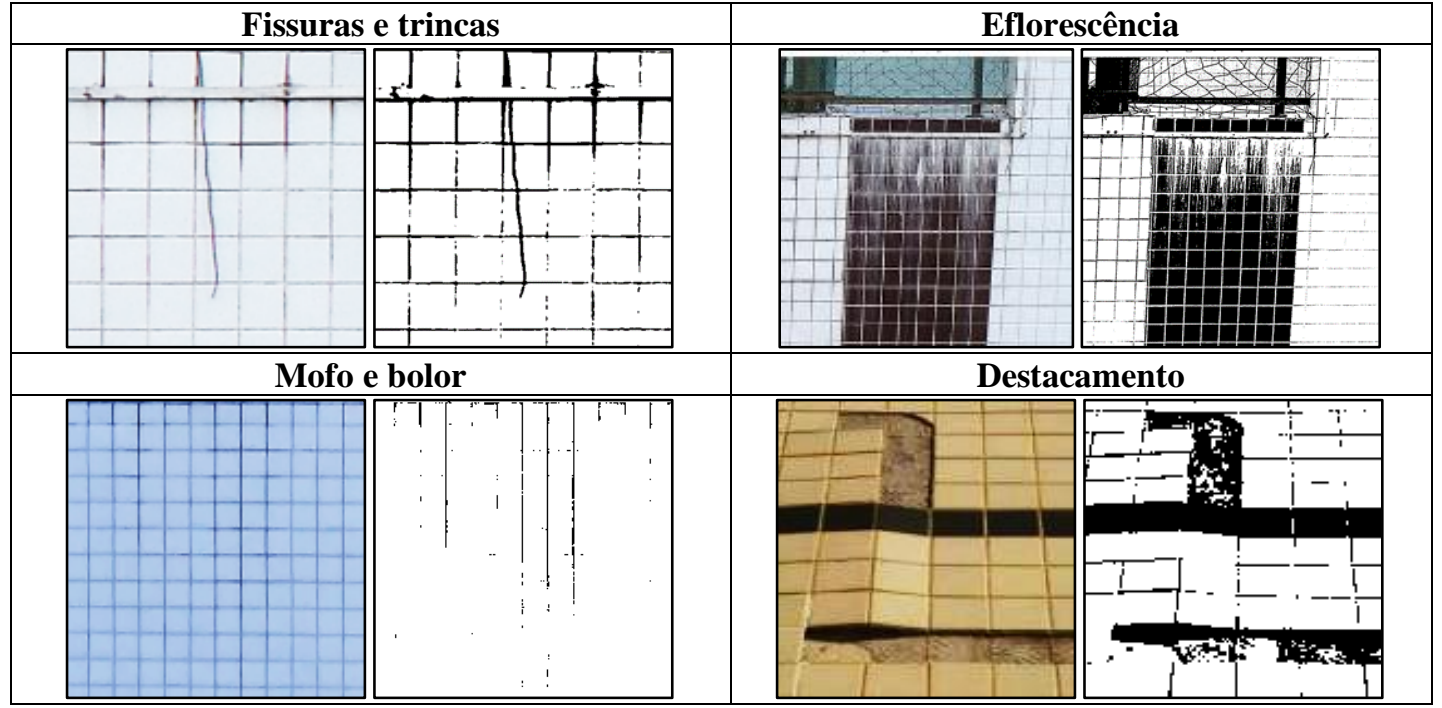

No entanto, vale a pena considerar o risco de trabalho em altura a que o profissional de alpinismo industrial está submetido. Por exemplo, se um VANT cair, pode ser substituído, o que não ocorre com a vida humana em serviço de altura.

Nesse método tradicional de inspeção também devem ser consideradas as variáveis custo e tempo, as quais podem ser superiores quando comparadas com opções tecnológicas que têm surgido nos últimos anos, como os sistemas robóticos de alpinismo (RIOBÓ et al., 2018), sistemas de detecção e alcance de luz (LIDAR) ou VANT de asas rotatórias (ACOSTA et al., 2019), os quais, equipados com diferentes tipos de câmeras ou sensores, permitem otimizar o processo de inspeção em altura.

Entre as opções tecnológicas para inspeção, o VANT de asas rotatórias é o dispositivo tecnológico mais acessível em termos de disponibilidade comercial e simplicidade de operação. Enfatiza-se que essa aeronave nada mais é do que um equipamento com mobilidade bastante flexível, que pode carregar, a depender das características de cada modelo, diferentes tipos de sensores úteis para procedimentos de inspeção.

Para a análise visual de manifestações patológicas, não influencia o meio de coleta de fotografias. Nesse sentido, um profissional pode estar munido dos mesmos sensores e descer de balancim fazendo diversos registros das fachadas de um edifício com resultados similares. Comparam-se, então, a rapidez e a segurança envolvida, bem como o custo de se realizar um registro completo da fachada com VANT ou por um profissional de alpinismo industrial.

Autores como Kim et al. (2016) e Emelianov, Bulgakow e Sayfeddine (2014) realçam as vantagens da utilização do VANT, notadamente pelo aumento da velocidade e pela expansão da cobertura para atividades de coleta de informações e imagens, além da redução do risco de acidentes das pessoas, inerente aos trabalhos de inspeção em altura.

\section{VANT para detecção de manifestações patológicas}

Segundo o Ministério da Defesa (BRASIL, 2015), o VANT é todo e qualquer tipo de aeronave que pode ser controlada nos três eixos e que não necessite de pilotos embarcados para ser guiada. Essas aeronaves são controladas a distância por meios eletrônicos e computacionais, sob a supervisão de humanos, ou mesmo sem sua intervenção, por meio de algoritmos de controle, navegação e planejamento de trajetória autônomos. São classificadas de acordo com as características aerodinâmicas, tais como asas fixas, asas rotatórias, dirigíveis e asas batedoras (ANGELOV, 2012), conforme a Figura 2.

Resultados de diferentes estudos analisados permitem inferir que o VANT de asas rotatórias apresenta características mais adequadas para inspeções verticais (HUNG et al., 2018; ÁLVARES, 2016; MELO JUNIOR, 2016; MELO, 2016; IRIZARRY; COSTA, 2016). Essas aeronaves realizam pouso e decolagem vertical mediante um sistema de sustentação que permite alta manobrabilidade e estabilidade no ar. Tais características têm impulsionado o crescimento das aplicações de aeronaves enquadradas nessa classificação, particularmente em atividades de inspeção (AMORIM; SILVA; CHRISTAKOU, 2012). 
Figura 2 - Tipos de VANT por características aerodinâmicas

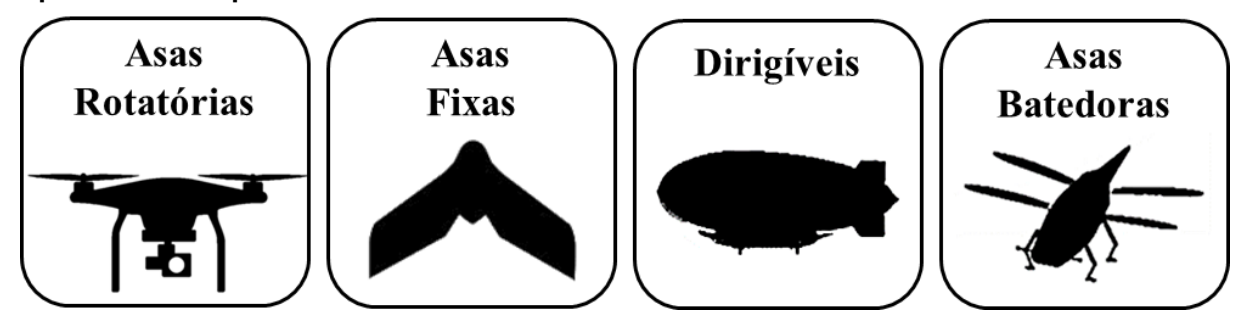

Da mesma forma, pesquisadores vêm testando o uso de diferentes tipos de câmeras e sensores embarcados no VANT para a detecção de manifestações patológicas em infraestrutura. Uma fração desses estudos tem ênfase nas fachadas de edifícios, na maioria dos casos em revestimentos argamassados e edificações de mediana altura (KERLE et al., 2019; SERRAT et al., 2019; WALTER et al., 2019; MELO JUNIOR, 2016). Nesses casos, os dispositivos de coleta embarcados mais populares são as câmeras digitais, câmeras termográficas infravermelhas e escâneres móveis (ACOSTA et al., 2019).

Esses dispositivos de coleta geralmente viabilizam a produção de três tipos de recursos visuais:

(a) fotografias digitais ou termogramas parciais;

(b) modelos tridimensionais; e

(c) modelos ortomosaicos (ACOSTA et al., 2019; MELO JUNIOR, 2016).

Seguidamente, o engenheiro ou arquiteto pode analisar os ativos visuais gerados e indicar as possíveis falhas no sistema de fachada com as devidas recomendações de ações corretivas, para então elaborar o laudo de inspeção predial de fachadas.

Trabalhos de Kerle et al. (2019) e Fernandez Galarreta, Kerle e Gerke (2015) demonstraram a importância das informações geométricas na detecção de danos, em particular nas aberturas em telhados e fachadas. Nesse sentido, o uso de escâneres móveis embarcados permite realizar uma varredura a laser, que, em síntese, deveria possibilitar a produção de um modelo tridimensional que represente de forma fidedigna a geometria da edificação analisada, permitindo detectar diferentes manifestações patológicas, como fissuras, destacamentos e deslocamentos anômalos em elementos estruturais.

Nesse contexto, o laboratório francês de sensoriamento remoto ONERA utilizou o VANT para embarcar diferentes tipos de escâneres a laser móveis. Embora as primeiras experiências tenham falhado devido à instabilidade das aeronaves empregadas, mais recentemente conseguiram resultados excelentes combinando o escâner Riegl VUX-1 com o hexacóptero DJI Matrice 600 (KERLE et al., 2019). As principais desvantagens dessa combinação de dispositivos são o elevado custo de aquisição e a exigência de conhecimentos especializados para o planejamento e execução de voos e o processamento de dados.

Por outro lado, quanto ao estado da arte da termografia infravermelha, diversos estudos de grande relevância têm sido desenvolvidos para analisar e validar a viabilidade de aplicação da técnica para a detecção de manifestações patológicas. No entanto, deve-se salientar que grande parte deles é desenvolvida em ambiente laboratorial, e aqueles que são explorados em campo contam com a utilização da câmera em visada de nível terrestre, evidenciando a necessidade de mais estudos sobre a aplicação da técnica embarcada em VANT (ANDRADE et al., 2019).

Ellenberg et al. (2016) expõem a capacidade de usar essas aeronaves equipadas com câmeras digitais e termográficas para a identificação rápida de destacamentos e seu tamanho na inspeção de pontes. Mader et al. (2016) e Entrop e Vasenev (2017) apresentaram resultados sobre o desenvolvimento de um protocolo para voos com drones para o campo de termografia de edifícios. Esses dois estudos ressaltam, entre as principais vantagens da abordagem apresentada, a capacidade de identificar rapidamente locais onde existem destacamentos e infiltrações, geralmente não visíveis a olho nu, nem por câmeras digitais ou escâneres móveis.

Entretanto, ficou constatado que a combinação de ambos os sistemas ainda apresenta algumas limitações, sendo vulneráveis à capacidade de carga do VANT e às oscilações climáticas que influenciam no voo e nos dados obtidos no termograma, além das reflexões de diferentes objetos vizinhos que podem interferir nos resultados (ANDRADE et al., 2019). Todavia, os avanços tecnológicos e as pesquisas de ampliação desses modelos tendem a superar tais desvantagens e a garantir cada vez mais a eficácia da ferramenta. 
Nas condições atuais, o conjunto VANT e câmera digital tem-se apresentado como a alternativa mais acessível em termos de custo-benefício para a inspeção de fachadas (MELO JUNIOR, 2016), especialmente porque aeronaves já são comercializadas com esse tipo de câmera incorporada, o que fornece mais confiabilidade ao desempenho de ambas as tecnologias, tanto do hardware como do software.

Recentemente, autores como Serrat et al. (2019) e Walter et al. (2019) estudaram o uso combinado de VANT com câmera digital embarcada para inspeção de fachadas argamassadas.

A partir dos resultados, os autores constataram que o processo de coleta de imagens digitais com essa aeronave possui amplo potencial de uso, possibilitando a identificação de manifestações patológicas como manchas de sujeira, expansão no revestimento e/ou pintura, falhas de execução e fissuras tanto horizontais como verticais. As principais limitações foram o alcance operacional e a duração do voo (KERLE et al., 2019).

Em síntese, a câmera digital embarcada no VANT propicia uma captura de imagens em alta resolução de todos os pontos de interesse nas fachadas (WALTER et al., 2019), inclusive sendo possível o mapeamento fotográfico completo da fachada por meio de técnicas de fotogrametria digital, cuja associação ao processamento computacional das imagens viabiliza a construção de modelos tridimensionais e ortomosaicos, os recursos mais comuns com essa técnica (PATRIOTA, 2017; MELO JUNIOR, 2016).

Destaca-se que o mapeamento fotográfico completo do estado de conservação da fachada pode minimizar a ocorrência de omissões na inspeção de manifestações patológicas quando comparado com uma análise de fotografias que registram unicamente pontos de interesse em segmentos parciais da fachada.

O processamento computacional das fotografias digitais se dá por meio de softwares de fotogrametria digital, que, em conjunto com o VANT e a câmera digital embarcada, completam o pacote tecnológico.

O princípio de funcionamento da maioria desses softwares baseia-se na correspondência estéreo densa (Dense Stereo Matching - DSM), que essencialmente consiste na correlação automática de conjuntos de pixels homólogos em fotos distintas (smartmatches) para a obtenção das coordenadas tridimensionais de pontos contidos na superfície dos objetos fotografados, gerando, assim, o modelo geométrico de nuvem de pontos (TAVANI et al., 2014; KOUTSOUDIS et al., 2019), a partir do qual é produzido o modelo tridimensional e, consequentemente, os ortomosaicos.

Contudo, atualmente há limitada informação científica sobre o estudo experimental desse tipo de mapeamento para detecção de manifestações patológicas em fachadas, particularmente quando se trata de revestimentos cerâmicos. A aplicação de técnicas de fotogrametria digital tem o potencial de padronizar o processo de registro e de documentação fotográfica, principalmente pelos requisitos de recobrimento e sequência de coleta inerentes à técnica. Conclui-se necessária uma avaliação qualitativa entre os três tipos de recursos visuais produzidos pelo pacote tecnológico, em termos de desempenho, para exibir anomalias nas fachadas de edificações de mediana e grande altura, em que o VANT mostra maiores benefícios.

\section{Metodologia}

A metodologia adotada neste trabalho abrangeu a realização de dois estudos de caso, um edifício de mediana altura e outro de grande altura, ambos com revestimento cerâmico de fachada, testando o desempenho do pacote tecnológico composto de VANT, de câmera digital e de software de fotogrametria digital como ferramentas para a inspeção de manifestações patológicas. Esse procedimento foi estruturado conforme o protocolo de atividades apresentado na Figura 3, considerando as seguintes etapas: pré-execução ou análise do projeto; execução ou coleta de imagens; pós-execução ou processamento de imagens para produção de modelos tridimensionais e ortomosaicos, seguido da análise comparativa do desempenho dos recursos visuais para o objetivo da detecção de ocorrências patológicas nas fachadas.

Neste protocolo, o conteúdo de formulários e checklist é apresentado sintetizado no Quadro 1. Onde o formulário de planejamento foi usado na pré-execução, permitindo sistematizar a análise do projeto de inspeção da edificação e padronizar o planejamento. O checklist para missão com VANT foi usado na etapa de execução do serviço para a preparação do voo, controle e operações de pouso e decolagem, objetivando estruturar o procedimento de inspeção em campo e tornar o fluxo de trabalho de captura de imagens mais eficiente, considerando requisitos de segurança e o uso apropriado do equipamento. Finalmente, a planilha flight log é um registro de dados dos voos que visa sintetizar a relação de todos os dados físicos dos voos realizados (BALLESTEROS, 2020). 
Figura 3 - Protocolo de atividades

\section{SERVIÇO DE INSPEÇÃO DE MANIFESTAÇÕES PATOLÓGICAS EM FACHADAS}

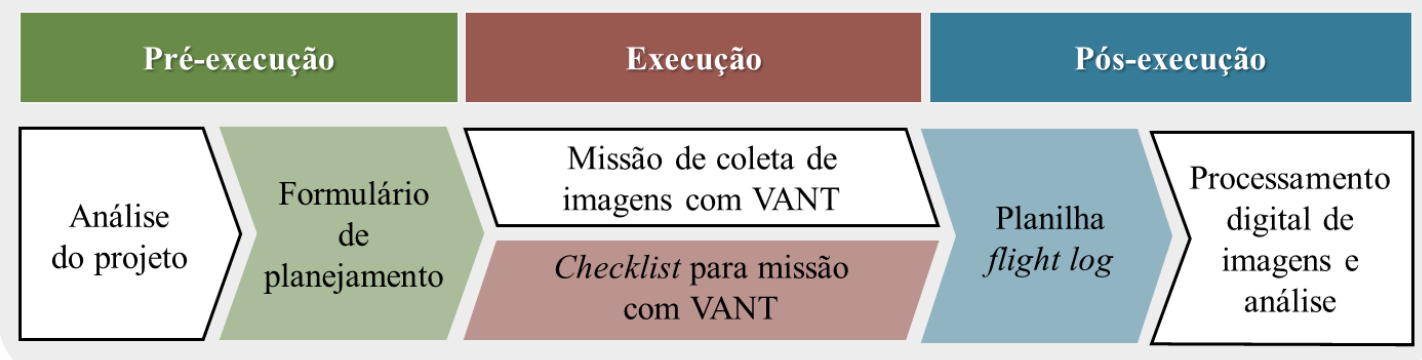

Quadro 1 - Conteúdo sintetizado de formulários e checklist desenvolvidos

\begin{tabular}{|l|l|l|}
\hline A: Formulário de planejamento & B: Checklist para missão & C: Planilha flight log \\
\hline 1. Informações edificação & 1. Cadastro voo & 1. Local, data, hora \\
\hline 2. Plano voo & 2. Atividades pré-decolagem & 2. Número fotos \\
\hline 3. Posicionamento câmera & 3. Atividades pós-decolagem & 3. Distância fachada (m) \\
\hline 4. Sobreposição fotografias & 4. Atividades pré-pouso & 4. Altitude máxima (m) \\
\hline 5. Sequência coleta imagens & 5. Atividades fim missão & 5. Duração voo (min) \\
\hline
\end{tabular}

Fonte: Ballesteros (2020).

\section{Pré-execução: análise do projeto}

A escolha das edificações foi efetuada na área urbana da cidade de Recife, PE, considerando o critério de altura e tipo de sistema de revestimento da fachada. Assim, para o primeiro estudo de caso foi selecionada uma edificação de mediana altura com 4 pavimentos e $16,5 \mathrm{~m}$ de altura (Figura 4a). Já para o segundo estudo de caso foi selecionado um edifício multifamiliar de grande altura com 16 andares e $48 \mathrm{~m}$ de altura (Figura 4b).

O dispositivo selecionado para a coleta das imagens aéreas foi o VANT Phantom 4 Pro V 2.0 com a câmera digital embarcada CMOS 1" $20 \mathrm{MP}$, ambos fabricados pela DJI (Figura 5). A escolha foi fundamentada, principalmente, pela confiabilidade e bons resultados apresentados por esse equipamento ou similares nas experiências piloto descritas por autores de diferentes estudos (HUNG et al., 2018; ÁLVARES, 2016; MELO JUNIOR, 2016; IRIZARRY; COSTA, 2016).

Operado por controle remoto com display HD de alta iluminação, o software de pilotagem utilizado foi o DJI Go app. Esse aplicativo, predeterminado no controle, auxiliou na captura de imagens e possibilitou o controle e monitoramento dos diferentes parâmetros de voo, como altitude da aeronave, velocidade, posicionamento GPS, distância à fachada, nível de bateria, alarmes dos sensores de proximidade e acompanhamento em tempo real da câmera incorporada ao VANT, permitindo a visualização de tudo o que foi sendo registrado.

Para o processamento das imagens, foi selecionado o software de fotogrametria digital PhotoScan, da fabricante Agisoft. Estudos realizados por Koutsoudis et al. (2019), Álvares (2016), Melo Junior (2016), Melo (2016) e Verhoeven (2011) enfatizam as vantagens desse software, que se tem apresentado como uma ferramenta de baixo custo, intuitiva, que proporciona modelos digitais com boa qualidade visual. A versão específica do software da Agisoft utilizado foi o PhotoScan Professional 1.4.0 build 5076 para sistema operativo Windows 64 bits.

Com o pacote tecnológico definido, o plano de voo foi elaborado de forma que a coleta de imagens satisfizesse os critérios mínimos do mapeamento das fachadas por meio de técnicas de fotogrametria digital. Dessa forma, as características abrangeram o posicionamento da câmera, a sobreposição das fotografias e a sequência de captura das imagens. 
Figura 4 - Edificações selecionadas para os estudos de caso
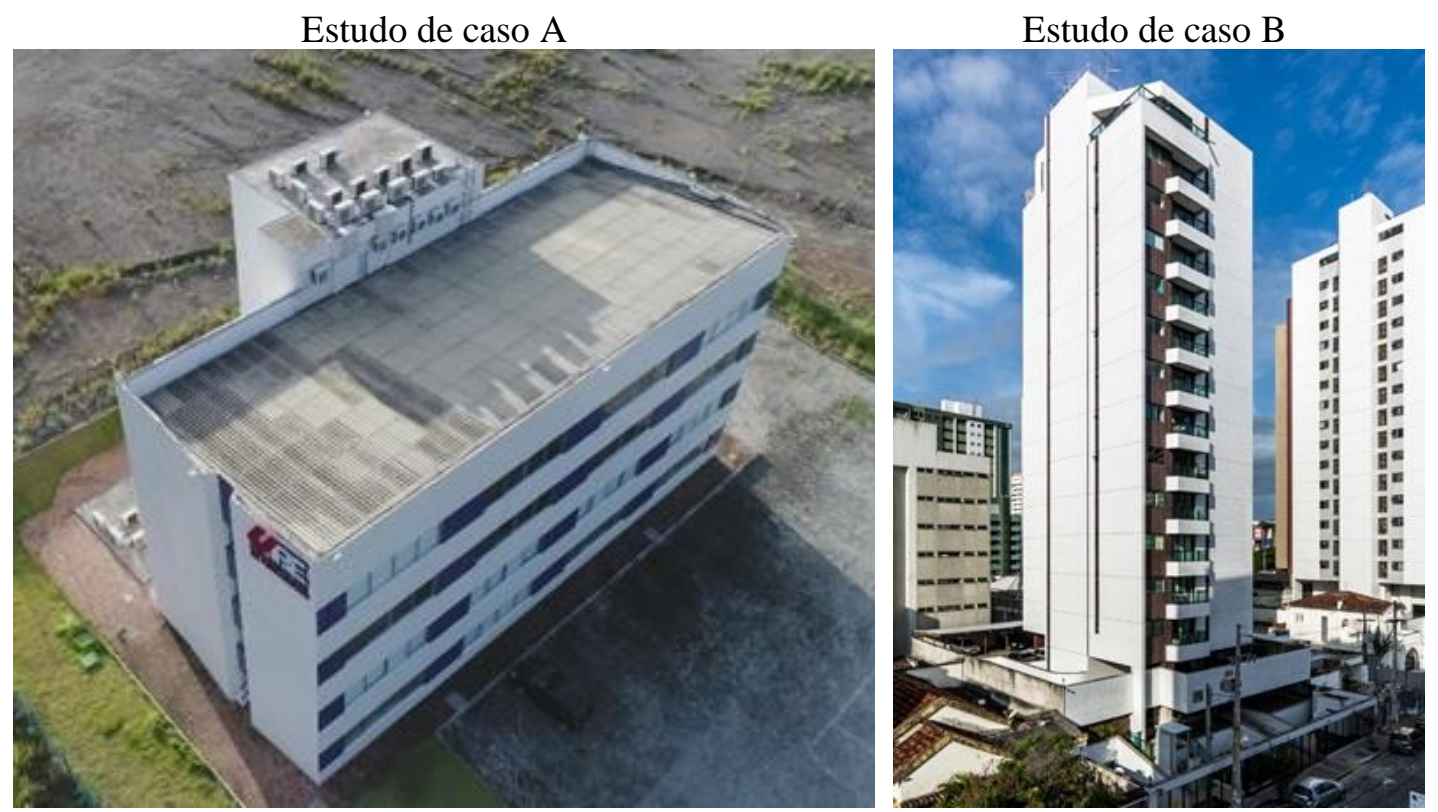

Figura 5 - Equipamento VANT utilizado
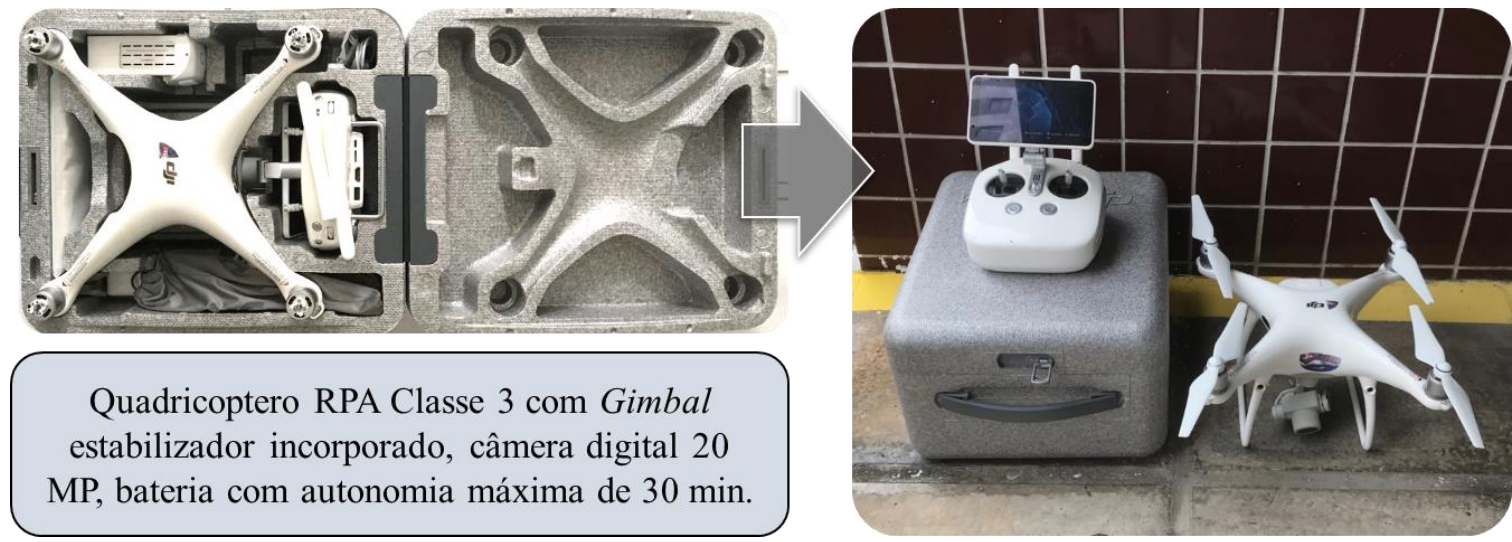

Quadricoptero RPA Classe 3 com Gimbal estabilizador incorporado, câmera digital 20 MP, bateria com autonomia máxima de $30 \mathrm{~min}$.

A principal característica do posicionamento das câmeras para as tomadas fotográficas foi o paralelismo entre si, procurando sempre a perpendicularidade ao plano da fachada estudada (MELO JUNIOR, 2016; YANG et al., 2015), sendo recomendável garantir uma sobreposição entre fotografias de 60-80\%, tanto longitudinal quanto lateral (GROETELAARS; AMORIM, 2012), além de manter uma relação da distância entre a posição das estações na tomada fotográfica e a distância das estações para a fachada fotografada entre 0,1 e 0,5 , pois, se for muito pequena, a correlação automática dos pontos é facilitada, mas a precisão geométrica na reconstrução digital da fachada é prejudicada (PIERROT-DESEILLIGNY; DE LUCA; REMONDINO, 2011).

Finalmente, na sequência de captura das imagens, recomenda-se seguir uma direção de coleta paralela ao lado com maior dimensão da fachada, sequência horizontal (varredura em faixas horizontais) quando a largura é superior, como no primeiro estudo de caso, e sequência vertical (varredura em faixas verticais) quando a altura é a maior, como no segundo estudo de caso. Assim, na Figura 6 são exemplificadas as diretrizes utilizadas para a definição da técnica de captura de imagens.

Por conseguinte, em concordância com os tópicos antes discutidos, os parâmetros adotados para a captura de imagens na pesquisa consideraram áreas de sobreposição entre as fotografias de aproximadamente 65-75\% nos sentidos longitudinal e lateral das faixas de voo do VANT. Do mesmo modo, a distância da estação para a fachada foi de $8 \mathrm{~m}$, e, consequentemente, a distância entre as estações na tomada fotográfica foi de $1,8 \mathrm{~m}$ 
no sentido vertical e de 3,2 m no sentido horizontal, permitindo uma relação de distâncias dentro dos intervalos exemplificados na Figura 6.

Figura 6 - Diretrizes da técnica de captura de imagens

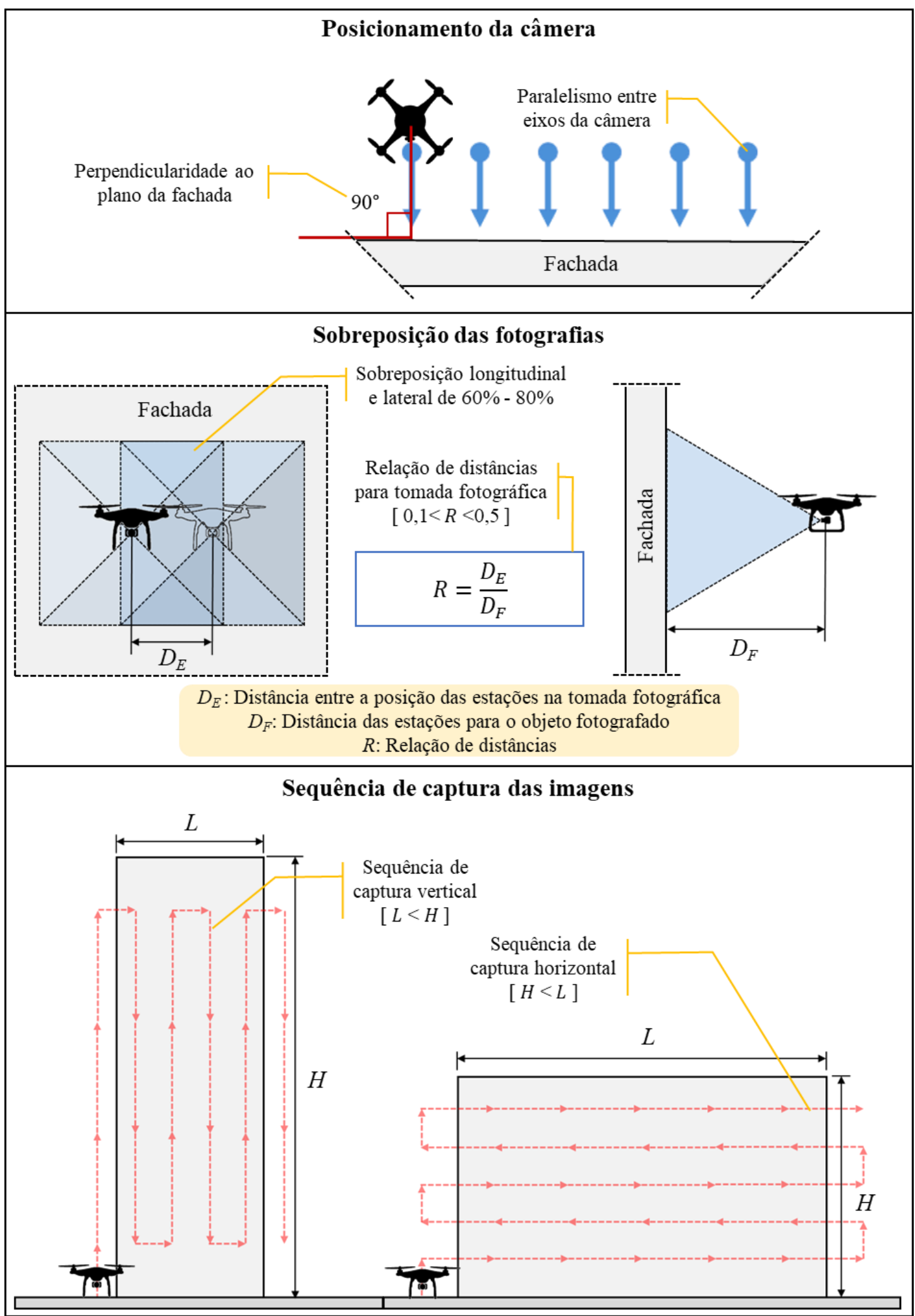




\section{Execução: coleta de imagens}

A coleta de imagens foi executada conforme o planejamento elaborado para ambos os estudos de caso, com operação manual da aeronave. Para todos os voos, pelo menos três membros da equipe de pesquisa foram envolvidos: o piloto, o observador que guiou o piloto para a coleta de imagens, e o observador que se concentrou na segurança do voo (aproximação a edificações, cabos de alta/média tensão, veículos, aeronaves, pássaros ou outros obstáculos que possam pôr em riscos o voo).

Foram realizados quatro voos para cada estudo de caso, coletando um conjunto de 169 imagens no primeiro estudo de caso e de 273 no segundo. Foi contabilizada a realização de um voo a cada decolagem e pouso realizados, inclusive para troca de memória SD ou recarregar a bateria, resultando em aproximadamente $1 \mathrm{~h}$ e 22 min da aeronave no ar, conforme apresentado na Tabela 1. Entre as informações registradas durante o voo por meio do App DJI Go, destacam-se a quantidade de ativos visuais coletados (fotos e vídeos), a distância, a altitude máxima e a duração de voo, todos registrados na planilha flight log.

As imagens foram armazenadas no formato TIFF seguindo a mesma ordem de captura, agrupando-as em arquivos que correspondem a cada uma das fachadas estudadas, permitindo que esses recursos ficassem prontos e organizados para se iniciar o processamento computacional por meio do software de fotogrametria digital.

\section{Pós-execução: processamento digital e análise}

O processamento computacional foi realizado utilizando um computador fabricado pela Dell, com sistema operacional de 64 bits, Windows 7 Professional, processador Intel Xeon $1.90 \mathrm{GHz}$ (2 processadores) e memória instalada (RAM) de $16 \mathrm{~GB}$, que permite processar até 200 fotografias assumindo a resolução das fotografias do Phantom 4 Pro da ordem de 20 MP (AGISOFT, 2018), que, de modo estimativo e dependendo dos parâmetros de qualidade selecionados, pode demorar até $80 \mathrm{~h}$. Salienta-se que o tempo de processamento está relacionado diretamente à combinação dos parâmetros de modelagem escolhidos.

Para o primeiro estudo de caso foram processadas de uma vez só todas as fotografias, contendo as oito fachadas da edificação em um único modelo tridimensional. Já para o segundo estudo de caso foi necessária a modelagem parcial para cada fachada da edificação, uma vez que o número de fotografias total superou a capacidade de processamento do computador (AGISOFT, 2018). Enfatiza-se que, para todas as etapas de processamento, foram selecionados os parâmetros máximos de qualidade admitidos pelo software PhotoScan (Quadro 2), objetivando a produção de recursos visuais de maior qualidade visual (ACOSTA et al., 2019).

No total foram produzidos cinco modelos digitais tridimensionais (Figura 7). O primeiro correspondente ao estudo de caso A, com uma nuvem densa que superou os 22 milhões de pontos e mais de 500 mil faces construídas no mesh, e os quatro seguintes retratam o estudo de caso B, totalizando mais de 148 milhões de pontos na nuvem densa e 27 milhões de faces construídas no mesh. Destaca-se que, a partir das nuvens de pontos, o modelo pode ser exportado e trabalhado em diversos aplicativos de modelagem tridimensional, plataformas BIM e ortomosaicos. Este último recurso foi gerado para cada fachada estudada.

De forma geral, o tempo de processamento registrado para a construção dos modelos tridimensionais foi de 73 h e 27 min para o edifício do estudo de caso A. Já no caso do estudo B foram 166 h e 17 min registrados no total. A somatória deste tempo corresponde às etapas de alinhamento de fotografias (align photos), construção da nuvem densa de pontos (build dense cloud), construção da malha (build mesh) e texturização do modelo (build texture).

O tempo de produção total de cada recurso visual, além do tempo de processamento, contemplou tempos inerentes à coleta $\mathrm{e}$ ao armazenamento das fotografias, bem como o tempo de exportação do ortomosaico no caso particular desse recurso. A Tabela 2 apresenta o resumo dos tempos empregados para produzir cada um dos três ativos visuais gerados na pesquisa experimental (fotografias digitais, modelos tridimensionais e ortomosaicos). 
Tabela 1 - Planilha flight log

\begin{tabular}{c|c|c|c|c|c|c|c|c}
\hline $\mathbf{N}$ & Local & Data & Hora & $\begin{array}{c}\text { Fase do } \\
\text { estudo }\end{array}$ & $\begin{array}{c}\text { Número } \\
\text { de fotos }\end{array}$ & $\begin{array}{c}\text { Distância } \\
\text { da fachada } \\
(\mathbf{m})\end{array}$ & $\begin{array}{c}\text { Altitude } \\
\text { máxima } \\
(\mathbf{m})\end{array}$ & $\begin{array}{c}\text { Duração } \\
\text { do voo } \\
\text { (min) }\end{array}$ \\
\hline $\mathbf{8}$ & \multicolumn{8}{c}{ Estudo de caso A - Mediana altura } \\
\hline $\mathbf{1}$ & Curado & $03 / 03 / 19$ & $10: 02$ & Execução & 66 & 8 & 14,50 & 11 \\
\hline $\mathbf{2}$ & Curado & $03 / 03 / 19$ & $10: 15$ & Execução & 20 & 8 & 14,50 & 5 \\
\hline $\mathbf{3}$ & Curado & $03 / 03 / 19$ & $10: 23$ & Execução & 61 & 8 & 14,50 & 8 \\
\hline $\mathbf{4}$ & Curado & $03 / 03 / 19$ & $13: 07$ & Execução & 22 & 8 & 16,50 & 5 \\
\hline $\mathbf{1}$ & Madalena & $08 / 05 / 19$ & $9: 00$ & Execução & 97 & 8 & 46,00 & 13 \\
\hline $\mathbf{2}$ & Madalena & $08 / 05 / 19$ & $9: 31$ & Execução & 49 & 8 & 46,00 & 14 \\
\hline $\mathbf{3}$ & Madalena & $08 / 05 / 19$ & $12: 10$ & Execução & 101 & 8 & 48,00 & 15 \\
\hline $\mathbf{4}$ & Madalena & $08 / 05 / 19$ & $12: 31$ & Execução & 26 & 8 & 46,00 & 11 \\
\hline
\end{tabular}

Quadro 2 - Parâmetros de processamento utilizados

\begin{tabular}{|c|c|c|}
\hline Etapa & \multicolumn{2}{|c|}{ Parâmetros } \\
\hline \multirow{3}{*}{ Align photos } & Accuracy & Highest \\
\cline { 2 - 3 } & Pair preselection & Generic \\
\cline { 2 - 3 } Build dense cloud & Nuvem esparsa & Max \\
\hline \multirow{3}{*}{ Build mesh } & Quality & High \\
\cline { 2 - 3 } & Depth filtering & Aggressive \\
\cline { 2 - 3 } & Nuvem densa & Max \\
\cline { 2 - 3 } & Surface type & Arbitrary 3D \\
\cline { 2 - 3 } Build texture count & Figh \\
\hline \multirow{2}{*}{ Build orthomosaic } & Max \\
\cline { 2 - 3 } & Mapping mode & Adaptiveorthophoto \\
\cline { 2 - 3 } & Blending mode & Mosaic \\
\hline \multirow{2}{*}{ Tlang mode } & Mosaic \\
\hline
\end{tabular}

Figura 7 - Modelos digitais tridimensionais produzidos (Continua...)

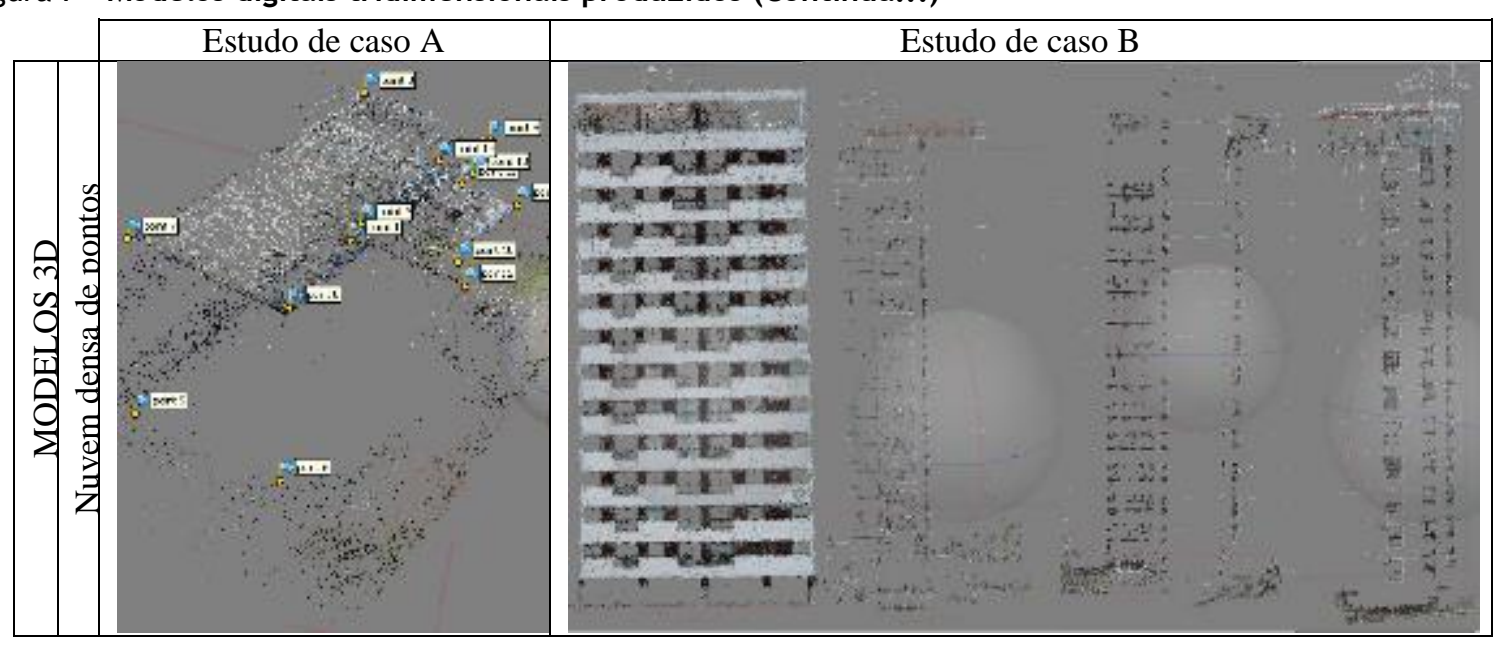


Figura 7 - Modelos digitais tridimensionais produzidos (continuação)

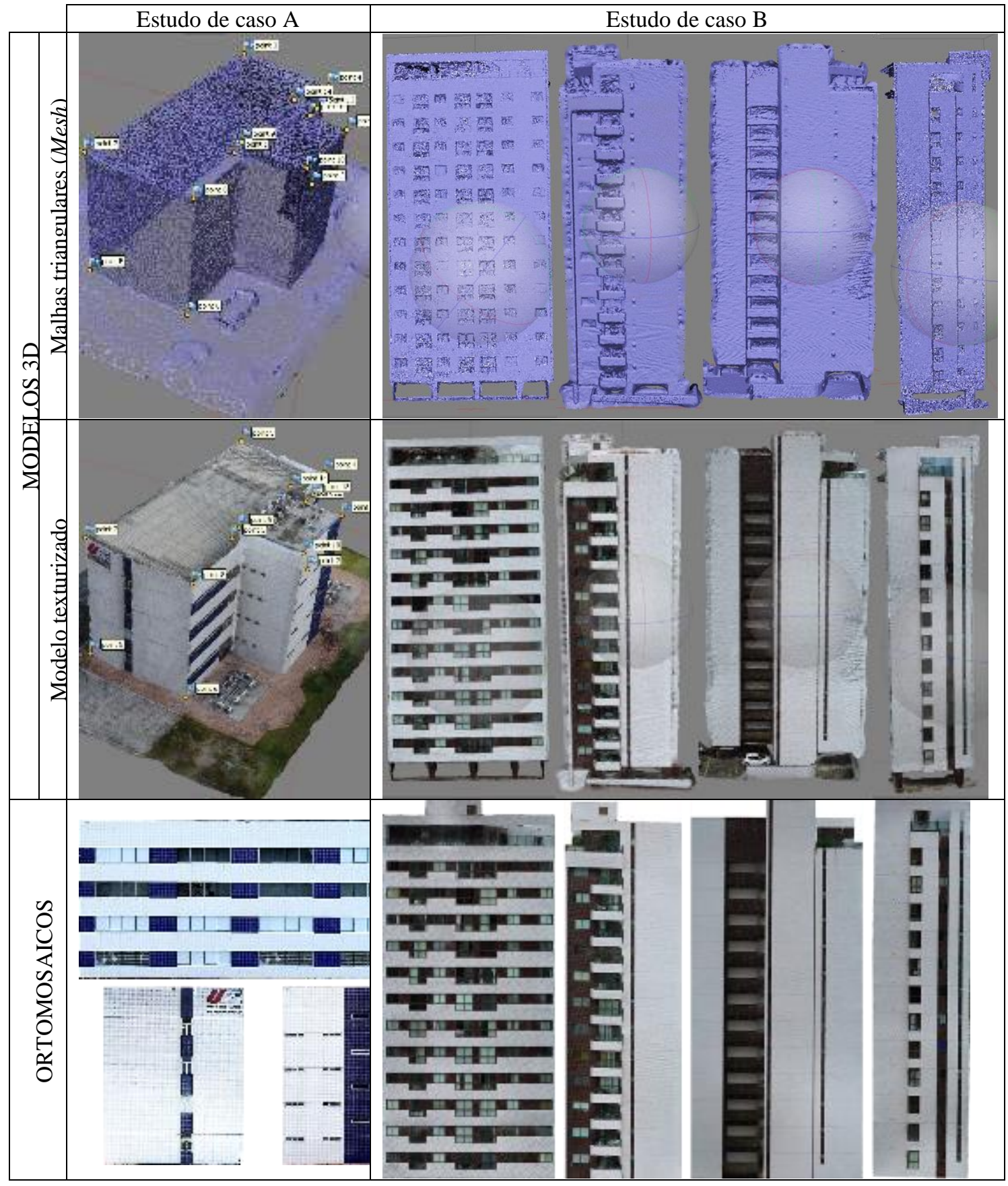

130 Ballesteros, R. D.; Lordsleem Junior, A. C. 
Tabela 2 - Detalhamento de tempos para produção de cada ativo visual

\begin{tabular}{l|c|c|c|c|c|c}
\hline \multirow{2}{*}{ Etapa de produção } & \multicolumn{7}{|c}{ Tempo de produção [horas] } \\
\cline { 2 - 7 } & \multicolumn{2}{|c|}{ Fotografias } & \multicolumn{2}{c}{ Modelo 3D } & \multicolumn{2}{c}{ Ortomosaico } \\
\cline { 2 - 7 } & $\begin{array}{c}\text { Estudo de } \\
\text { caso A }\end{array}$ & $\begin{array}{c}\text { Estudo de } \\
\text { caso B }\end{array}$ & $\begin{array}{c}\text { Estudo de } \\
\text { caso A }\end{array}$ & $\begin{array}{c}\text { Estudo de } \\
\text { caso B }\end{array}$ & $\begin{array}{c}\text { Estudo de } \\
\text { caso A }\end{array}$ & $\begin{array}{c}\text { Estudo de } \\
\text { caso B }\end{array}$ \\
\hline Coleta de fotografias & 3,20 & 3,70 & 3,20 & 3,70 & 3,20 & 3,70 \\
\hline Armazenamento & 0,20 & 0,25 & 0,20 & 0,25 & 0,20 & 0,25 \\
\hline Align photos & - & - & 15,65 & 27,95 & 15,65 & 27,95 \\
\hline Build dense cloud & - & - & 42,67 & 82,08 & 42,67 & 82,08 \\
\hline Build mesh & - & - & 12,08 & 50,85 & 12,08 & 50,85 \\
\hline Build texture & - & - & 2,58 & 4,87 & 2,58 & 4,87 \\
\hline Build orthomosaic & - & - & - & - & 0,47 & 0,67 \\
\hline Exportação de & - & - & - & - & 0,07 & 0,8 \\
\hline ortomosaicos & - & 3,95 & 76,38 & 169,70 & 76,92 & 170,45 \\
\hline TOTAL & 3,40 & & & & & \\
\hline
\end{tabular}

Com os três recursos visuais produzidos, passou-se ao método de detecção de manifestações patológicas, que consistiu na inspeção visual de cada recurso, agrupados e ordenados em função do estudo de caso, número de fachada e tipo de produto. Na sequência, a varredura visual em busca de manifestações patológicas foi realizada de cima para baixo e da esquerda para a direita, individualmente para cada fachada, bem como para cada recurso visual produzido. Quando uma manifestação patológica era visualizada, devia ser classificada, identificada, verificada in situ, localizada e documentada no croqui da fachada, para finalmente produzir os mapas de danos para cada fachada (Figura 8).

\section{Resultados e discussões}

A aplicação do pacote tecnológico estudado resultou na produção dos três recursos visuais. Os modelos tridimensionais apresentaram resultados satisfatórios em sua reconstrução geométrica, ajudando na visualização espacial do edifício.

Por outro lado, os ortomosaicos, além de excelente resolução espacial (pixels por polegada), conseguiram representar fielmente a vista ortogonal verdadeira da fachada, facilitando a localização das manifestações patológicas no plano geral da fachada.

Finalmente, as fotografias digitais originais, um recurso que não sofreu retificações ou distorções, apresentaram o melhor desempenho em termos de exibição de manifestações patológicas, proporcionando maior confiabilidade para a inspeção visual.

Analisando o tempo de produção desses recursos visuais, observam-se grandes diferenças entre os dois estudos de caso, conforme apresentado na Figura 9. Essa divergência se dá principalmente pela estratégia de processamento adotada. No primeiro caso foi criado unicamente um modelo que, embora permita acelerar o processamento, não permitiu o alinhamento da totalidade das fotografias carregadas, reduzindo a qualidade do produto. Por outro lado, no estudo de caso B o processamento foi realizado para cada fachada, o que facilitou a compreensão espacial do software e, por conseguinte, permitiu o alinhamento da totalidade das fotografias carregadas para cada modelo das fachadas.

$\mathrm{Na}$ Tabela 3 são apresentados os resultados da identificação das manifestações patológicas, individualmente para cada recurso visual produzido, bem como para cada estudo de caso. A manifestação patológica visualizada com maior frequência nos estudos de caso foi a eflorescência, equivalente a $55 \%$ das manifestações patológicas detectadas, seguida das fissuras e trincas, com $26 \%$, e, finalmente, o mofo e o bolor, com $19 \%$.

Salienta-se que nenhuma ocorrência de destacamento foi detectada, seja pelas limitações da câmera digital para registrar características dessa manifestação numa fase precoce, seja pela inexistência da patologia nos estudos de caso. Nesse contexto, $100 \%$ dos achados foram identificados nas fotografias digitais, $52 \%$ nos ortomosaicos, e apenas $23 \%$ nos modelos tridimensionais texturizados. 
Figura 8 - Mapa de danos para as fachadas com achados patológicos

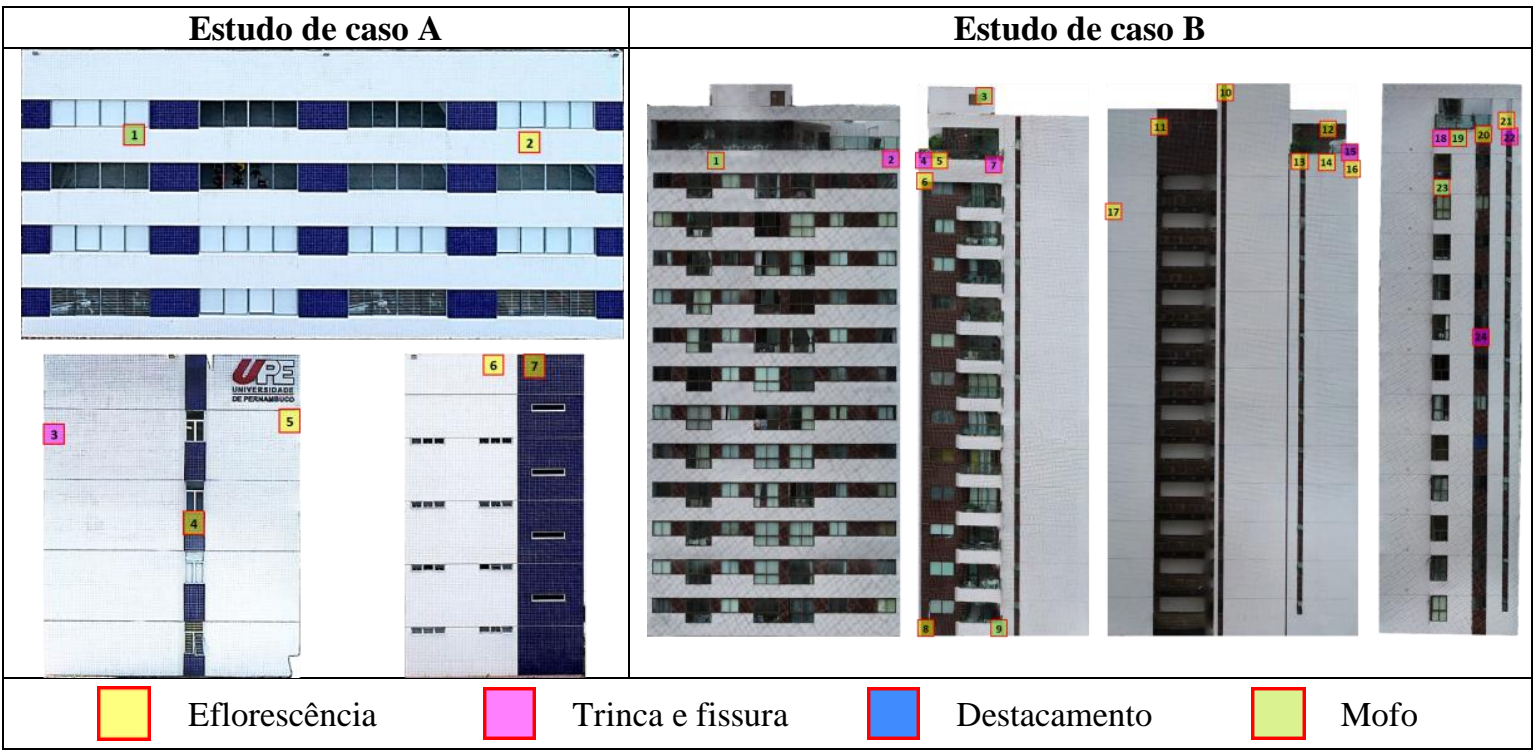

Figura 9 - Tempo total em horas para produção de recurso visual

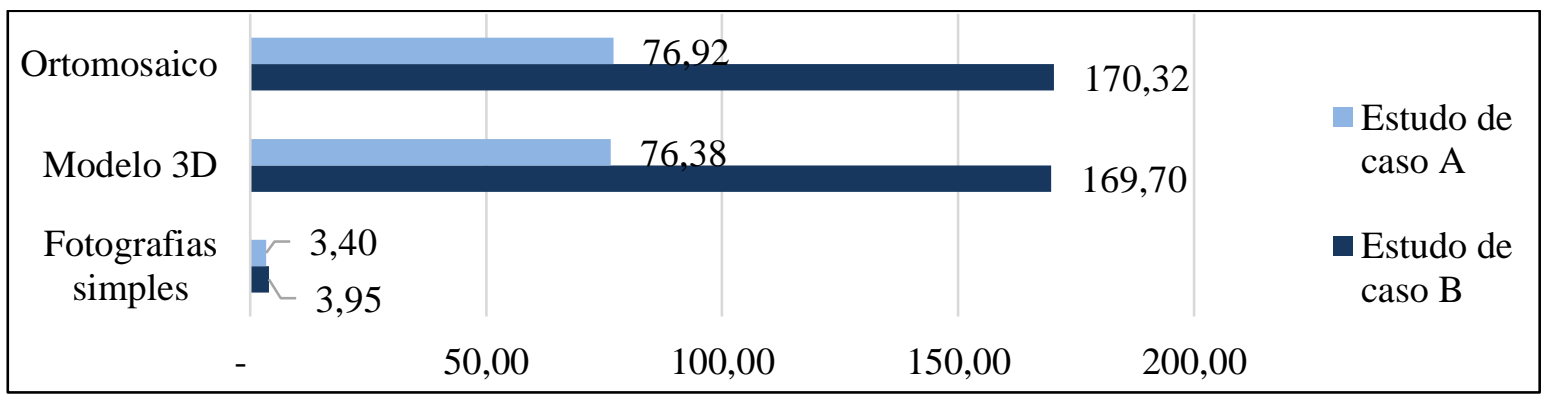

Tabela 3 - Manifestações patológicas detectadas

\begin{tabular}{l|l|c|c|c}
\hline \multirow{2}{*}{ Fachada } & \multirow{2}{*}{$\begin{array}{c}\text { Tipo de } \\
\text { patologia }\end{array}$} & \multicolumn{3}{c}{$\begin{array}{c}\text { Número de manifestações patológicas } \\
\text { detectadas }\end{array}$} \\
\cline { 3 - 5 } & & Fotografias & Modelo 3D & Ortomosaico \\
\hline \multirow{4}{*}{ Estudo de caso A } & Fissura e trincas & 1 & 0 & 0 \\
\cline { 2 - 5 } & Eflorescência & 5 & 2 & 5 \\
\cline { 2 - 5 } & Destacamento & 0 & 0 & 0 \\
\cline { 2 - 5 } & Mofo e bolor & 1 & 0 & 0 \\
\cline { 2 - 5 } & TOTAL & 7 & 2 & 2 \\
\hline \multirow{4}{*}{ Estudo de caso B } & Fissura e trincas & 7 & 1 & 8 \\
\cline { 2 - 5 } & Eflorescência & 12 & 3 & 0 \\
\cline { 2 - 5 } & Destacamento & 0 & 0 & 11 \\
\cline { 2 - 5 } & Mofo e bolor & 5 & 1 & 2 \\
\cline { 2 - 5 } & TOTAL & 24 & & \\
\hline
\end{tabular}

Para uma análise mais criteriosa, cada recurso visual foi avaliado em função de sua capacidade de exibir as manifestações patológicas. Os três recursos para inspeção foram classificados de 1 a 3 (1= pior, 2 = médio e 3 = melhor), de acordo com a adequação ou cumprimento dos objetivos do procedimento de inspeção, como apresentado na Tabela 4, no qual os valores percentuais representam a quantidade de achados identificados sobre o total do tipo de patologia.

Em uma segunda etapa, as pontuações na primeira etapa foram analisadas comparativamente levando em consideração a variável do tempo de produção (para cada recurso visual). Esses dados são apresentados na

132 Ballesteros, R. D.; Lordsleem Junior, A. C. 
Figura 10, na qual se percebe claramente que o ativo visual com maior eficácia para a detecção de manifestações patológicas corresponde às fotografias digitais originais. Esse recurso tem a classificação 3 (melhor) para exibição de manifestações patológicas, ligado a um tempo de produção notoriamente inferior quando comparado com as alternativas estudadas.

Em outros termos, o tempo de produção inferior das fotografias em relação a seu desempenho superior para a detecção de manifestações patológicas traduz-se numa melhor relação custo-benefício, que consequentemente denota maior eficiência para o processo de detecção de manifestações patológicas em fachadas.

As demais alternativas demandam grande custo de processamento computacional para serem elaboradas, característica que incrementa amplamente o tempo de produção. Esse tempo adicional não se justifica para o objetivo de inspeção de manifestações patológicas, tendo em vista o limitado desempenho individual dos modelos tridimensionais e ortomosaicos.

No entanto, as fotografias digitais coletadas não propiciaram o adequado mapeamento dos achados patológicos, já que individualmente cada imagem apenas representa determinada fração da fachada. Nesse contexto, torna-se necessário contar com alguma representação geométrica da fachada completa, sejam planos arquitetônicos ou ortomosaicos, que permitam a localização espacial da manifestação patológica.

Tabela 4 - Avaliação de recursos visuais

\begin{tabular}{l|c|c|c|c|c|c}
\hline Tipo de patologia & \multicolumn{2}{|c|}{$\begin{array}{c}\text { Classificação das } \\
\text { fotografias digitais }\end{array}$} & $\begin{array}{c}\text { Classificação do } \\
\text { modelo 3D }\end{array}$ & $\begin{array}{c}\text { Classificação do } \\
\text { ortomosaico }\end{array}$ \\
\hline Fissura e trincas & $100 \%$ & -3 & $13 \%$ & -1 & $25 \%$ & $>1$ \\
\hline Eflorescência & $100 \%$ & -3 & $29 \%$ & -1 & $76 \%$ & $>3$ \\
\hline Destacamento & - & - & - & - & - & - \\
\hline Mofo e bolor & $100 \%$ & -3 & $17 \%$ & -1 & $17 \%$ & $>1$ \\
\hline $\begin{array}{l}\text { Classificação } \\
\text { ponderada }\end{array}$ & $100 \%$ & $>3$ & $23 \%$ & -1 & $52 \%$ & $>2$ \\
\hline
\end{tabular}

Figura 10 - Gráfico comparativo pontuação - tempo de produção

Porcentagem de patologias visualizadas $(\%) \quad$ - - Tempo para produção do ativo visual (h)

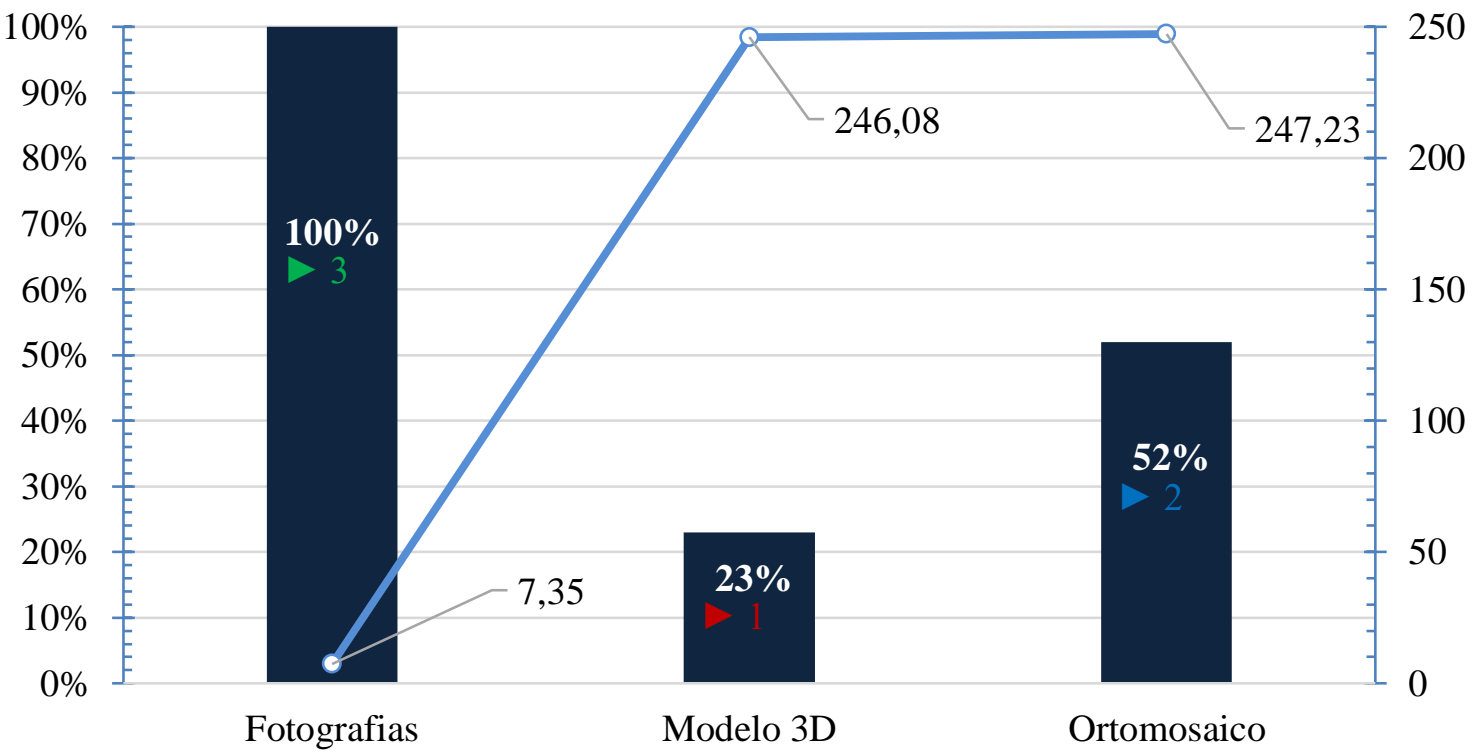


Em consequência, os ortomosaicos apresentaram utilidade fundamental para o serviço de inspeção. Embora seja o recurso que tenha demandado maior tempo de produção, combinado com as fotografias digitais, permitiu a localização espacial dos achados na vista ortogonal das fachadas completas, facilitando a construção dos mapas de danos, os quais auxiliam na produção de laudos técnicos mais instrutivos, em que a localização e a tipologia dos achados patológicos são claramente exibidas numa representação real da fachada, o que favorece as atividades de manutenção.

Por outro lado, os modelos tridimensionais mostraram-se menos eficazes para o tipo de inspeção estudado. Com um custo computacional elevado e deficiente exibição das manifestações patológicas, foi considerado um recurso menos adequado para a inspeção de fachadas. Não obstante, a fiel representação espacial da geometria da edificação é o principal atributo desse recurso, característica de grande utilidade para diferentes propósitos na indústria da construção civil, como o registro tridimensional de informações relativas à geometria ou arquitetura de edifícios históricos ou de patrimônio cultural, auxiliando em trabalhos de reforma, manutenção e até, possivelmente, reconstrução.

Com relação aos estudos de Serrat et al. (2019) e Walter et al. (2019), os resultados da pesquisa confirmaram o potencial da combinação do VANT com câmera digital embarcada para a detecção de eflorescência, mofo, bolor, fissura e trincas. Não obstante, o sistema de revestimento cerâmico de fachada, diferentemente dos revestimentos argamassados, não reflete visualmente estágios iniciais de destacamento. Nesse contexto, o uso de câmeras digitais é insuficiente para o estudo preventivo desse tipo de patologia, sendo necessárias câmeras térmicas infravermelhas ou testes de percussão.

Além dessa particularidade, não foram observadas diferenças substanciais entre os resultados fotográficos de revestimentos cerâmicos e argamassados na bibliografia analisada (WALTER et al. 2019; ACOSTA et al. 2019), enfatizando que características relativas à textura e à refletividade do material cerâmico não influenciaram significativamente no registro e na visualização das manifestações patológicas.

A partir dos resultados alcançados foram corroborados os benefícios inferidos das pesquisas de Patriota (2017) e Melo Junior (2016) quanto ao uso da técnica de fotogrametria digital para a coleta de imagens com VANT. Essa técnica, acompanhada dos checklist e de planilhas que compõem o protocolo desenvolvido, estruturou todo o procedimento de coleta e documentação de fotografias. Mesmo quando o processamento computacional não é pretendido, percebe-se que essa técnica propicia a padronização das fotografias em termos de sequência de coleta, paralelismo entre pontos de captura, perpendicularidade ao plano da fachada e, principalmente, sobreposição entre fotografias. Esta última permite registrar cada ponto da fachada em pelo menos três ângulos, diferentes, minimizando e até eliminando a ocorrência de omissões na inspeção da fachada.

\section{Conclusões}

De modo geral, e diante dos resultados alcançados, o pacote tecnológico composto de veículo aéreo não tripulado, câmera digital aérea e software de processamento foi validado para a inspeção de manifestações patológicas em fachadas com revestimento cerâmico, uma vez que os recursos visuais produzidos propiciaram a detecção de diferentes achados patológicos.

Particularmente, a aeronave e a câmera incorporada mostraram eficiência na coleta de imagens, proporcionando fotografias com qualidade satisfatória e dando agilidade aos processos. Da mesma forma, esse conjunto tecnológico se caracterizou pela versatilidade na locomoção vertical e horizontal, bem como pela praticidade para alcançar as regiões mais elevadas das edificações, atributos que, combinados, permitem atender aos critérios mínimos necessários para o mapeamento de fachadas com técnicas de fotogrametria digital.

Porém, como principal limitação, essa técnica de inspeção não dispensa a realização de testes de percussão ou, em alternativa, o uso de câmeras térmicas infravermelhas para a detecção preventiva de destacamentos em sistemas de revestimentos cerâmicos. As características visuais dessa manifestação patológica, num estágio inicial, não são facilmente reconhecíveis ao olho nu, da mesma forma que são difíceis de registrar numa câmera digital.

Entre os recursos produzidos na inspeção, os modelos tridimensionais e ortomosaicos apresentaram resultados limitados em função de seu desempenho para exibir manifestações patológicas. Por si sós, são considerados recursos pouco adequados para o tipo de inspeção em questão. Essa particularidade é inerente ao processamento por softwares de fotogrametria digital e se dá, essencialmente, porque, para a produção dos modelos, as imagens processadas são retificadas para se adequar à geometria do modelo construído, 
sofrendo alguma distorção e comprometendo a qualidade visual da imagem. No entanto, tendo em vista a conveniente representação geométrica da fachada no ortomosaico, considera-se um excelente recurso complementar para a produção de mapas de danos.

Por outro lado, as fotografias digitais mostraram claramente ser o recurso mais eficaz, em virtude do número de patologias detectadas, e mais eficiente, em função do tempo demandado para sua produção. Consequentemente, ostenta a melhor relação custo-benefício, constituindo-se como a melhor escolha para o procedimento de inspeção de manifestações patológicas em fachadas, inclusive vislumbrando a viabilidade de automatizar o processo de detecção de manifestações patológicas com técnicas de processamento digital de imagens (PDI) voltadas à extração de atributos, ou seja, reconhecimento e classificação de características ou padrões de uma fotografia.

Esse método de detecção automatizada de anomalias, geralmente usado em fábricas de revestimentos cerâmicos para controle de qualidade, pode ser incluído no pacote tecnológico e ser aproveitado para procedimentos de inspeção. Por fim, estima-se que a associação da qualidade padronizada de fotografias coletadas com técnicas de fotogrametria digital, aliadas a um algoritmo computacional treinado para o reconhecimento de características das manifestações patológicas, permitiria otimizar amplamente o serviço de inspeção de fachadas.

\section{Referências}

ACOSTA, L. M. et al. Exploring technological alternatives to the visual inspection method in the built environment. IOP Conference Series: Earth and Environmental Science, v. 222, n. 1, p. 1-10, 2019.

AGISOFT PhotoScan. User Manual. Professional edition. Version 1.4. 2018.

AGUILAR, G. Inspeção predial de fachadas com drones à luz da ABNT NBR 5674:2012: manutenção de edificações. 2018. Disponível em: https://www.linkedin.com/pulse/inspe\% C3\%A7\%C3\%A3o-predialde-fachadas-com-drones-\%C3\%A0-luz-da-abnt-gabriel-aguilar/?published=t. Acesso em: 19 maio 2018.

ALMEIDA, M. Manifestações patológicas em revestimentos cerâmicos de fachada em três estudos de caso na cidade de Balneário Camboriú. Florianópolis, 2004. 174 f. Dissertação (Mestrado em Arquitetura e Urbanismo) - Programa de Pós-graduação em Arquitetura e Urbanismo, Universidade Federal de Santa Catarina, Florianópolis, 2004.

ÁLVARES, J. S. Mapeamento 3D de canteiros via imagens coletadas com veículo aéreo não tripulado (VANT). Salvador, 2016. 156 f. Monografia (Graduação engenharia civil) - Escola Politécnica, Universidade Federal de Bahia, Salvador, 2016.

AMORIM, A. L.; SILVA, L. S.; CHRISTAKOU, E. D. Uso de VANT em documentação arquitetônica. In: SEMINÁRIO NACIONAL DE DOCUMENTAÇÃO DO PATRIMÔNIO ARQUITETÔNICO COMO USO DE TECNOLOGIAS DIGITAIS, 1., Belém, 2012. Anais [...] Belém, 2012.

ANDRADE, R. et al. Estado da arte da utilização da técnica de termografia da técnica de termografia embarcada em drones para inspeção de revestimentos de fachadas. In: TECNOLOGIA DE PROCESSOS E SISTEMAS CONSTRUTIVOS, 2., São Paulo, 2019. Anais [...] São Paulo, 2019.

ANGELOV, A. Sense and avoid in UAS: research and applications. Lancaster: Wiley, 2012.

BALLESTEROS, R. Inspeção de manifestações patológicas de fachadas utilizando Veículo Aéreo Não Tripulado (VANT): estudo exploratório. Recife, 2020. 220 f. Dissertação (Mestrado em Engenharia civil) Escola Politécnica de Pernambuco, Universidade de Pernambuco, Recife, 2020.

BAUER, E.; MILHOMEM, P. M.; AIDAR, L. A. Evaluating the damage degree of cracking in facades using infrared thermography. Journal of Civil Structural Health Monitoring, v. 8, n. 3, p. 517-528, 2018.

BRASIL. Ministério de Defesa. Voos de RPAS (drones): entenda a nova legislação do DECEA. 2015. Disponível em: https://www.decea.gov.br/?i=midia-e-informacao\&p=pg_noticia\&materia=voos-derpasdrones-entenda-a-nova-legislacao-do-decea. Acesso em: 25 out. 2018.

COSTA, I. et al. Ceramic materials in civil construction: a brief review. Research, Society and Development Journal, v. 8, n. 10, p. 107-121, 2019.

ELLENBERG, A. et al. Bridge deck delamination identification from unmanned aerial vehicle infrared imagery. Automation in Construction, v. 72, p. 155-165, 2016. 
EMELIANOV, S.; BULGAKOW, A.; SAYFEDDINE, D. Aerial laser inspection of buildings facades using quadrotor. In: CREATIVE CONSTRUCTION CONFERENCE, 1., Prague, 2014. Proceedings [...] Prague, 2014.

ENTROP, A.; VASENEV, A. Infrared drones in the construction industry: designing a protocol for building thermography procedures. In: NORDIC SYMPOSIUM ON BUILDING PHYSICS, 11., Trondheim, 2017. Proceedings [...] Trondheim, 2017.

FERNANDEZ GALARRETA, J.; KERLE, N.; GERKE, M. Uav-based urban structural damage assessment using object-based image analysis and semantic reasoning. Natural Hazards and Earth System Sciences Journal, n. 15, p. 1087-1101, 2015.

FREITAS, A.; FRANÇA, T.; FRANÇA, P. Patologias de fachadas. Revista Pensar Engenharia, v. 1, n. 2 , p. 1-11, 2013.

GALLETTO, A.; ANDRELLO, J. M. Patologia em fachadas com revestimentos cerâmicos. In: CONGRESSO INTERNACIONAL SOBRE PATOLOGIA E RECUPERAÇÃO DE ESTRUTURAS, 9., João Pessoa, 2013. Anais [...] João Pessoa, 2013.

GROETELAARS, N. J.; AMORIM, A. L. Dense Stereo Matching (DSM): conceitos, processos e ferramentas para criação de nuvens de pontos por fotografias. In: SIGRADI 2012 - CONGRESO DE LA SOCIEDAD IBEROAMERICANA DE GRÁFICA DIGITAL, 12., Fortaleza, 2012. Anais [...] Fortaleza 2012.

HORSTH, A. A. et al. Pathology in facade ceramic coating. Revista Educação, Meio Ambiente e Saúde, v. 8, n. 1, p. 27-38, 2018.

HUNG, M. N. W. B. et al. Levantamento com veículo aéreo não tripulado para geração de modelo digital do terreno em bacia experimental com vegetação florestal esparsa. Revista Ra'e Ga Espaço Geográfico em Análise, v. 43, p. 215-231, 2018.

IRIZARRY, J.; COSTA, D. B. Exploratory study of potential applications of unmanned aerial systems for construction management tasks. Journal of Management in Engineering, v. 32, n. 3, p. 05016001, 2016.

JUST, A.; FRANCO, L. S. Descolamentos dos revestimentos cerâmicos de fachada na cidade do Recife. São Paulo, 2001. Boletim Técnico da Escola Politécnica da USP.

KERLE, N. et al. UAV-based structural damage mapping: a review. International Journal of GeoInformation, v. 9, n. 1, p. 1-23, 2019.

KIM, S. et al. Lessons learned from unmanned aerial system-based 3D mapping experiments. In: ASC ANNUAL INTERNATIONAL CONFERENCE, 52., Provo, 2016. Proceedings [...] Provo, 2016.

KOUTSOUDIS, A. et al. Multi-image 3D reconstruction data evaluation. Journal of Cultural Heritage, v. 5, n. 1, p. 73-79, 2019.

LOPES, M. et al. Análise de manifestações patológicas em fachadas de edifícios. In: CONGRESSO TÉCNICO E CIENTÍFICO DA ENGENHARIA E DA AGRONOMIA, 5., Maceió, 2018. Anais [...] Alagoas, 2018.

MADER, D. et al. Potential of UAV-Based laser scanner and multispectral camera data in building inspection. In: THE INTERNATIONAL ARCHIVES OF THE PHOTOGRAMMETRY, REMOTE SENSING AND SPATIAL INFORMATION SCIENCES, 41., Prague, 2016. Anais [...] Prague, 2016.

MELO JUNIOR, C. M. Metodologia para geração de mapas de danos de fachadas a partir de fotografias obtidas por veículo aéreo não tripulado e processamento digital de imagens. Brasília, 2016. 408 f. Tese (Doutorado em estruturas e construção civil) - Faculdade de Tecnologia, Universidade de Brasília, Brasília, 2016.

MELO, R. R. S. Diretrizes para inspeção de segurança em canteiros de obra por meio de imageamento com veículo aéreo não tripulado (VANT). Salvador, 2016. 160 f. Dissertação (Mestrado em engenharia civil) - Escola Politécnica, Universidade Federal de Bahia, Salvador, 2016.

MELO, R. R. S.; COSTA, D. B. Uso de veículo aéreo não tripulado (VANT) para inspeção de logística em canteiros de obra. In: SIMPÓSIO BRASILEIRO DE GESTÃO E ECONOMIA DA CONSTRUÇÃO, 9. São Carlos, 2015. Anais [...] São Carlos, 2015. 
PATRIOTA, R. C. Mapeamento de fachadas usando aeronave remotamente pilotada. Curitiba, 2017. Monografia (Especialização em VANT em aplicações civis e comerciais) - Curso de Pós-Graduação em VANTs (Drones) em Aplicações Civis e Comerciais, Pontifícia Universidade Católica do Paraná, Curitiba, 2017.

PIERROT-DESEILLIGNY, M.; DE LUCA, L.; REMONDINO, F. Automated image-based procedures for accurate artifacts 3D modeling and orthoimage generation. Geoinformatics CTU FCE. 2011. Disponível em: http://cipa.icomos.org/fileadmin/template/ doc/PRAGUE/113.pdf. Acesso em: 10 maio 2019.

POSSAN, E.; DEMOLINER, C. A. Desempenho, durabilidade e vida útil das edificações: abordagem geral. Revista Técnico-Científica do CREA-PR, v. 1, n. 1, p. 1-14, 2013.

REAGAN, D.; SABATO, A; NIEZRECKI, C. Feasibility of using digital image correlation for unmanned aerial vehicle structural health monitoring of bridges structural health monitoring. SAGE Publishing, v. 17, n. 3, p. 289-302, 2017.

RIOBÓ, J. et al. Nuevos sistemas robóticos de inspección e intervención en rehabilitación de fachadas. Anales de Edificación, v. 4, n. 2, p. 69-74, 2018.

SERRAT, C. et al. Exploring conditions and usefulness of UAVs in the BRAIN Massive Inspections Protocol. Open Engineering Journal, v. 1, n. 9, p. 1-6, 2019.

TAVANI, S. et al. Building a virtual outcrop, extracting geological information from it, and sharing the results in Google Earth via OpenPlot and Photoscan: an example from the Khaviz Anticline (Iran).

Computers \& Geosciences, v. 63, p. 44-53, 2014.

VDR. Vida De Reis Alpinismo industrial. Apostila de treinamento e técnicas de acesso por cordas. 2019. Disponível em: http://viadereis.com.br/assets/cartilha-via-de-reis-alpinismo.pdf. Acesso em: 02 abr. 2019.

VERHOEVEN, G. Taking computer vision aloft: archaeological three-dimensional reconstructions from aerial photographs with photoscan. Archaeological Prospection, v. 18, n. 1, p. 67-73, 2011.

WALTER, B. et al. Uso do VANT para identificação das manifestações patológicas de fachadas: estudo de caso em edificações. In: CONGRESO LATINO-AMERICANO DE PATOLOGÍA DE CONSTRUCCIÓN DE CONTROL DE CALIDAD EN LA CONSTRUCCIÓN, 17., Chiapas, 2019. Anais [...] Chiapas, 2019.

YANG, X. C. et al. Building facade recognition using oblique aerial images. Journal of Remote Sensing, v. 7, n. 8, p. 10562-10588, 2015

YOUNG, H.; SEONGHYUK, H. Three-dimensional digital documentation of cultural heritage site based on the convergence of terrestrial laser scanning and unmanned aerial vehicle photogrammetry. International Journal of Geo-Information, v. 9, n. 1, p. 1-14, 2019.

Ramiro Daniel Ballesteros Ruiz

Departamento Engenharia Civil, Escola Politécnica | Universidade de Pernambuco | Rua Benfica, 455, Madalena | Recife - PE - Brasil | CEP 50720-001 | Tel.: (11) 95913-0030 | E-mail: rdbr@poli.br

Alberto Casado Lordsleem Junior

Departamento Engenharia Civil, Escola Politécnica | Universidade de Pernambuco | Tel.: (81) 3184-7566 | E-mail: acasado@poli.br

\section{Ambiente Construído}

Revista da Associação Nacional de Tecnologia do Ambiente Construído

Av. Osvaldo Aranha, $99-3^{\circ}$ andar, Centro

Porto Alegre - RS - Brasil CEP 90035-190

Telefone: +55 (51) 3308-4084

Fax: +55 (51) 3308-4054

www.seer.ufrgs.br/ambienteconstruido

E-mail: ambienteconstruido@ufrgs.br 